\title{
Turismo, midiatização e amorosidade: Sinalizadores para a mutação das narrativas que valorizam os territórios turísticos
}

\section{Tourism, mediatization and lovingness: Signals for the mutation of narratives that valorize tourist territories}

\author{
Maria Luiza Cardinale Baptista \\ Universidade de Caxias do Sul, Brasil \\ malu@pazza.com.br
}

\begin{abstract}
Resumo
O artigo propõe a discussão sobre os processos de midiatização do turismo, como decorrentes de produções comunicacionais complexas, que sinalizam inflexões e agendamentos turísticos e, na contemporaneidade, vivem sob a demanda de mutação, de tal forma que acompanhe a transformação do mercado turístico. Trata-se de abordagem transdisciplinar, envolvendo estudos relativos à midiatização, da área da Comunicação Social e Cultura, estudos do Turismo e Esquizoanálise, como perspectiva que possibilita abordar aspectos psicocomunicacionais. $O$ artigo resulta de cartografia bibliográfica, debate nas rodas de conversa do Amorcomtur! e pesquisas relativas a territórios turísticos. Propõe o Turismo Amoroso, no sentido de pautado pela ética da relação, e autopoiético, que seja potencialmente campo de reinvenção de si mesmo e dos sujeitos envolvidos.
\end{abstract}

Palavras-chave: turismo; midiatização; amorosidade; narrativa; territórios; Amorcomtur.

\begin{abstract}
This paper discusses tourism mediatization processes as the result of complex communications productions that convey inflections and tourism schedules and, in modern times, are subject to the demand for change in order to accompany the tourist market. This is a cross-disciplinary approach involving mediatization studies from the field of Social Communication and Culture, Tourism studies and Schizoanalysis, which makes it possible to address psychological and communications aspects. The paper is the result of a literature review, debated in group discussions held by the Amorcomtur! study group, and studies on different tourist locations. It proposes Loving Tourism (Turismo Amoroso), based on ethical relationships and autopoiesis, with the potential to reinvent itself and the subjects involved.
\end{abstract}

Keywords: tourism; mediatization; lovingness; narrative; territories; Amorcomtur.

\section{Para início de 'conversa'...}

Midiatização do Turismo. Narrativas do turismo e territórios. Trilhas para a construção de um turismo marcado pela amorosidade. Estas são as temáticas centrais deste artigo, que se propõe a discutir a potência do Turismo, como um devir - 'o que deve vir a ser' - atividade de amorosidade, e os processos de midiatização, ou seja, de expressão e codificação do turismo pelas mídias, envolvendo a trama dos meios de Comunicação Social disponíveis. Discute o contraponto entre a midiatização, como estratégia da máquina capitalista de produção do turismo, e a emergência e necessidade de um 'turismo amoroso', no sentido da ética da relação, do cuidado com o outro, da atenção e consideração aos aspectos da ecologia 
profunda, dos entrelaçamentos entre os diversos sujeitos do turismo e os territórios físicos, emocionais, culturais em que eles se deslocam.

O artigo é uma produção teórica que resulta dos estudos do Amorcomtur! Grupo de Estudos em Comunicação, Turismo, Amorosidade e Autopoiese, que lidero na Universidade de Caxias do Sul, no Programa de Pós-Graduação em Turismo e Hospitalidade (PPGTURH). Esse grupo, no entanto, tem entrelaçamentos com várias outras instituições, como a Universidade Federal do Amazonas, em Manaus, e a Universidade de Coimbra, em Portugal. $\mathrm{O}$ artigo tem correspondência, também, com diversas investigações em curso, que coordeno diretamente ou que oriento, e que me permitem refletir sobre as implicações das relações midiáticas e da construção das narrativas sobre o turismo, como dispositivo de valorização ou desvalorização dos territórios turísticos. Trata-se, ainda, do resultado de trabalho que vem sendo realizado na Universidade de Caxias do Sul, com mestrandos e pós-graduandos, também em 'percursos' acadêmicos (formalmente chamados de 'disciplinas', expressão com a qual não concordo), intitulados Narrativas Visuais e Processos de Midiatização do Turismo e Comunicação-Trama e Subjetividade no Turismo. Os encontros desses 'percursos' têm como características as rodas de conversa e envolvem produções práticas e reflexivas, especialmente em grupo, de tal maneira a construir percepções e a permitir uma análise sobre a midiatização do turismo e a amorosidade.

A produção também decorre diretamente de pesquisas realizadas, por mim, na Universidade de Caxias do Sul (UCS) e na Universidade Federal do Amazonas (UFAM), no Sul e no Norte do Brasil, respectivamente. São elas: Desterritorialização Desejante em Turismo e Comunicação: Narrativas Especulares e de Autopoiese, e Trama Amorcomtur! (UCS/BRASIL); e Usina de Saberes Amazônicos: Narrativas de Viagens Investigativas, como pesquisadora visitante sênior, e Entrelaços Caosmóticos com Saberes Amazônicos: Percorrendo as Trilhas Inscriacionais da 'Ciência em Movimento', na Sociedade e Cultura da Amazônia (UFAM), em pós-doutoramento.

A orientação teórica do Amorcomtur!, em sentido teórico mais amplo, é a da amorosidade e da autopoiese, tendo com fundamentação autores da Biologia Amorosa e do Conhecimento, como os chilenos Humberto Maturana e Francisco Varela; da Esquizoanálise, como Félix Guattari e Suely Rolnik; da Teoria da Complexidade e Epistemologia do Conhecimento, como Edgar Morin e Boaventura de Souza Santos, bem como a perspectiva da mutação da Ciência, com Fritjof Capra, Roberto Crema e llya Prigogine. A abordagem do Turismo é feita com o referencial teórico transdisciplinar, que possibilita compreender seus processos e práticas, em um espectro mais amplo e ecossistêmico, em combinação com autores da área como Susana Gastal e Marutchka Moesch.

Em termos de estratégia de texto, o artigo propõe uma viagem que começa com a sinalização da visão contemporânea de ciência, que possibilite compreender a midiatização e o turismo, em um primeiro momento, para perceber as inscrições de amorosidade, como essenciais para os processos e práticas do turismo, e suas expressões nas narrativas. As narrativas referidas aqui são, especialmente, as narrativas midiáticas, ou seja, dos meios de Comunicação Social, compreendidas como narrativas-trama, o que significa que são produzidas em ecossistemas comunicacionais amplos, com imbricações na diversas dimensões sociais. Vale ressaltar que este artigo corresponde a uma reflexão teórico-conceitual, ainda que em conexão (e decorrência de) com pesquisas empíricas e toda a experiência dos processos de aprendizagem da pós-graduação em Turismo, em Comunicação, nas 
Universidades mencionadas e nas práticas cotidianas e intensas de aprendizagem Amorcomtur!.

\section{Do ecossistema científico para o turístico e comunicacional}

Para compreender a discussão de midiatização do turismo, na perspectiva que é trabalhada aqui, é preciso considerar os pressupostos científicos que orientam o trabalho do Amorcomtur. No título geral do artigo, a palavra 'mutação' está sendo usada como uma referência direta ao livro, intitulado O Ponto de Mutação, de Capra (1991), o que significa propor que as grandes narrativas, da Ciência e as midiatizadas, estão em consonância com a mutação maior, sinalizada pelos estudos contemporâneos. Nesse sentido, também, a emergência da palavra 'ecossistema' associada à Ciência, neste ponto do texto, já sinaliza para a perspectiva sistêmica e para o fato de que esse sistema é vinculado ao que vem sendo chamado de Ecologia Profunda, ${ }^{1}$ por Capra (1997), e outros autores. O artigo está em sintonia também com os estudos produzidos na Amazônia Brasileira, na Universidade Federal do Amazonas (UFAM), especialmente por Monteiro (2011) e Colferai (2014).

O novo paradigma pode ser chamado de uma visão de mundo holística, que concebe o mundo como um todo integrado, e não como uma coleção de partes dissociadas. Pode também ser denominado visão ecológica, se o termo "ecológica" for empregado num sentido muito mais amplo e mais profundo que o usual. A percepção ecológica profunda reconhece a interdependência fundamental de todos os fenômenos, e o fato de que, enquanto indivíduos e sociedade estamos todos encaixados nos processos cíclicos da natureza (e, em última análise, somos dependentes desses processos). (Capra, 1997: 25)

Tem-se, aqui, claramente, pressupostos que rompem com a perspectiva da Ciência Clássica, que caracterizou a chamada Revolução Científica, com a emergência da racionalidade e a concepção antropocêntrica, cujos expoentes foram Renè Descartes, Isaac Newton e Francis Bacon. Capra (1997) alerta para o fato de que não se precisa romper totalmente com o paradigma anterior, mas compreender a mutação. Nesse sentido, é muito importante destacar o momento em que ele explica que "[...] a ecologia profunda faz perguntas profundas a respeito dos próprios fundamentos da nossa visão de mundo e do nosso modo de vida modernos, científicos, industriais, orientados para o crescimento e materialistas" (Capra, 1997: 26). O que está em jogo, portanto, segundo o autor, é uma perspectiva ecológica, que questiona a visão de mundo anterior, levando em conta a complexidade do que ele chamou de 'a teia da vida': "a partir da perspectiva de nossos relacionamentos uns com os outros, com as gerações futuras e com a teia da vida da qual somos parte.” (ibid.).

Dizer isso, sobre o ecossistema científico, implica reconhecer que tanto o turismo quanto os processos de midiatização são processos que ocorrem em plena 'teia da vida', entrelaçados com ecossistemas mais amplos, de muitas conexões, visíveis e invisíveis, que passam também por uma mutação no modo de serem abordados. A Ciência, o conhecimento que se produz a respeito desses processos, portanto, não se pauta pelo esforço para 'delimitar a área', o campo de saber, propriamente dito, nem tampouco por metodologias rígidas que dissequem

\footnotetext{
${ }^{1}$ O termo foi proposto pelo filósofo norueguês Arne Naess, em 1973, com as seguintes orientações, em termos de visão de mundo: harmonia com a natureza, toda a natureza tem valor intrínseco, igualdade entre as diferentes espécies, objetivos materiais a serviço de objetivos maiores de autorrealização, planeta tem recursos limitados, tecnologia apropriada e ciência não dominante, aproveitamento máximo dos recursos e reciclagem, reconhecimento de existência de biorregiões e de tradições das minorias (Goldim, 1999).
} 
o objeto, como se fosse possível esquadrinhá-lo, para, posteriormente, expor seus pedaços, numa demonstração mecânica de uma racionalidade científica. As bases aqui, para discussão, são outras.

Assim, como vem sendo destacado, entende-se que os processos de midiatização e do turismo são empreendidos em meio a complexos sistemas interligados com múltiplos outros sistemas, produzindo a composição ecossistêmica, cuja expressão visível e materializada é que eu venho também chamando de 'engrenagem maquínica'.2 Bem, vamos aos poucos. Para frisar, reitero o que já venho ressaltando: turismo e midiatização - assim como a midiatização do turismo - são produções desencadeadas e realizadas em sistemas complexos interligados. A esses sistemas complexos, que Capra (1997) refere como a 'teia da vida', tenho atribuído a palavra 'trama': daí, os conceitos de 'comunicação-trama', 'narrativas-trama', 'turismo-trama', 'subjetividade-trama', que venho propondo nos meus estudos. Sugiro a transposição, a partir do conceito de comunicação-trama, que apresentei, mais consistentemente, em 2000:

Comunicação é interação de sujeitos, através do fluxo de informações entre eles, numa espécie de trama-teia complexa, composta tanto de elementos visíveis quanto invisíveis, corporais e incorporais, significantes e a-significantes, podendo ser ou não mediada por dispositivos tecnológicos, na constituição de algo como um campo de força de encontro de energias, decorrente dos universos de referência de cada sujeito envolvido. Quer dizer, encontro de universos de sujeito, universos subjetivos. (Baptista, 2000: 33-34).

Considerando esse conceito, pode-se compreender a dimensão de complexidade dos processos de midiatização e do turismo, produzidos em grandes engrenagens sociotécnicas e midiáticas e que constituem a base sistêmica dos deslocamentos. Essas grandes engrenagens estão conectadas com todas as instâncias sociais da economia de mercado, para lembrar uma fala de Sodré (1987), sobre a televisão, e orientam-se por uma lógica que Harvey (2005) vai chamar de capitalismo por espoliação. Para além disso, a grande engrenagem, ou grande ecossistema, constitui-se por uma complexa teia-trama de fios entrelaçados que a constituem concretamente, mas também por agenciamentos abstratos, o que significa que há dimensões invisíveis, inaudíveis, imperceptíveis na materialidade, mas que constituem o que os estudos da Esquizoanálise vão chamar de 'plano de imanência' ou 'fluxos incorporais a-significantes' (Guattari, 1992). São agenciamentos de forças abstratas que, muitas vezes, geram os desfechos das movimentações em direção aos destinos turísticos, mas que não são mensuráveis ou visualizados nitidamente, se a concepção não estiver relacionada a essa dimensão de ecologia profunda a que venho me referindo. ${ }^{3}$ Vale a explicação de Capra (1997: 25-26), nesse sentido:

\footnotetext{
${ }^{2} \mathrm{O}$ termo 'engrenagem maquínica' deriva de uma determinada concepção de máquina, que não se restringe à máquina mecânica, com peças que são engatadas entre si em mecanismo repetitivos, portanto, previsíveis e passíveis de serem alterados, conforme a intenção dos sujeitos. A engrenagem maquínica é uma superestrutura composta de engendramentos materiais, concretos e abstratos, formados também por filamentos de intensidades de matérias diversas, inclusive, nos níveis das partículas subatômicas. O que move o mundo são esses grandes engendramentos cósmicos de entrelaçamentos formados pelos laços visíveis e invisíveis. Assim, várias áreas do conhecimento, como a Esquizoanálise, a Biologia Amorosa e a Ecologia Profunda, por exemplo, vão abordar 'máquinas autopoiéticas', em contraponto a um sistema forte, castrador e imobilizador dos sujeitos e dos processos de vida, porque é voltado aos interesses do capital e do poder econômico e político.

${ }^{3}$ Vale aqui a referência direta ao texto muito interessante de Akerlof e Shiller (2009), no texto intitulado "O espírito animal: como a psicologia humana impulsiona a economia e sua importância para o capitalismo global".
} 
A ecologia rasa é antropocêntrica, ou centralizada no ser humano. Ele vê os seres humanos como situados acima ou fora da natureza, como a fonte de todos os valores, e atribui apenas um valor instrumental, ou de "uso", à natureza. A ecologia profunda não separa seres humanos - ou qualquer outra coisa - do meio ambiente natural. Ela vê o mundo, não como uma coleção de objetos isolados, mas como uma rede de fenômenos que estão fundamentalmente interconectados e interdependentes. A ecologia profunda reconhece o valor intrínseco de todos os seres vivos e concebe os seres humanos apenas como um fio particular na teia da vida.

Assim, pode-se compreender que a teia da vida é o território de produção do sistema de vida, ou seja, o próprio Ecossistema, em que estão entrelaçados sistemas vários: econômicos, políticos, comunicacionais, turísticos, subjetivos, sem que se possa isolar esses sistemas, porque, na prática, eles só existem 'em relação', ou seja, 'entrelaçados'. Então, vale lembrar que a matriz significacional da palavra sistema deriva do grego synhistanai (colocar junto). Nesse sentido, está a explicação de Heinz von Foerster, mencionada por Capra (1997: 39): “[...] entender as coisas sistemicamente significa, literalmente, colocá-las dentro de um contexto, estabelecer a natureza de suas relações.". Em outro ponto, Capra (1997: 44-45) esclarece:

Desde que os sistemas vivos, em todos os níveis, são redes, devemos visualizar a teia da vida como sistemas vivos (redes) interagindo à maneira da rede com outros sistemas (redes). [...] a teia da vida consiste em redes dentro de rede. Em cada escala, sob estreito e minucioso exame, os nodos da rede se revelam como redes menores.

A partir da abordagem desses aspectos que situam o conceito de ecossistema, na perspectiva da ecologia profunda, da teia da vida, pode-se avançar para a compreensão dos processos de midiatização e do turismo. Ambas as áreas - Comunicação e Turismo - tiveram desenvolvimento histórico correlato com os processos do capitalismo, do desenvolvimento entrelaçado de objetos e tecnologias do cotidiano, dos processos econômicos, culturais e políticos, bem como da vinculação com o modo de se produzir conhecimento sobre esses processos, objetos e sujeitos envolvidos no ecossistema todo.

Em paralelo ao processo de industrialização e urbanização, decorrentes da Revolução Industrial, houve a transformação das paisagens, dos territórios, e também dos modos de se deslocar e comunicar. ${ }^{4}$ Seguiram-se tendências de deslocamentos, que passaram a ganhar novas motivações, mas também outras condições em relação às práticas históricas. As formas de comunicação também viveram processos de mutação, porque passaram a ganhar, cada vez mais, dispositivos maquínico-tecnológicos, que viabilizaram o enfrentamento de dimensões de tempo e distância. A humanidade foi gradativamente buscando se comunicar em menos tempo, em maiores distâncias, com um espectro cada vez maior de sujeitos. Essas

\footnotetext{
4 Interessante a abordagem de Magalhães (2016), no texto, Panorama histórico do Turismo: Do mundo moderno a contemporaneidade. Sobre o processo de desenvolvimento do capitalismo contemporâneo, o texto de Stropper (2012), O capitalismo pós-1990 e a emergência de novos pólos de poder. A temática também está bem desenvolvida, na tese de doutoramento de Stropper (2014), defendida na Universidade Federal do Rio Grande do Sul. Inflexão das ONGs ambientalistas após 1990: Um estudo sobre a atuação das ONGs no caso da Usina Hidrelétrica Belo Monte.
} 
transformações têm ligação direta com a transformação dos modos de produção, bem como os interesses políticos e econômicos. ${ }^{5}$

Vale dizer, Comunicação e Turismo são áreas estratégicas, em termos gerais, porque implicam em fluxos de capital, associados aos deslocamentos de sujeitos e de informações, sendo que esses processos têm vínculos diretos. O controle dos fluxos e o poder de acionar esses fluxos tem correspondência direta a valores financeiros e políticos, até pelas suas fortes conexões com máquinas produtivas desses sistemas. Dessas reflexões emergem questionamentos: a serviço de quem estão esses deslocamentos e fluxos? Quais são os focos dos sistemas que concentram os valores decorrentes desses processos? Na perspectiva da ecologia profunda, em que tudo está entrelaçado na teia da vida, que vida tem sido potencializada pelos fluxos de informação e deslocamentos turísticos? A proposição Amorcomtur! é que eles estejam a serviço da 'ética da relação', da amorosidade, autopoiese e ética do cuidado com o outro. As narrativas midiatizadas sobre o turismo são, nesse sentido, um importante território de sinalização para devires, que precisam ser repensados, compreendidos e direcionados para uma ecologia profunda da midiatização do turismo, em prol de processos de deslocamentos mais 'amorosos' e hospitaleiros.

\section{Reflexões sobre as narrativas e os processos de midiatização do turismo}

Há um ditado popular, no Brasil, que diz que "quem conta um conto aumenta um ponto". Essa frase, expressão dos saberes populares, pode ser interessante para refletir os processos de significação, a partir das narrativas. Quem conta um acontecimento turístico, uma viagem, ou descreve um destino turístico também 'aumenta um ponto'. Aumentando um ponto, produz outra significação, em relação aos territórios que existem, em si, agregando valores emocionais e intensidades abstratas, que vão, na repetição da midiatização, cristalizando-se em tendências interpretativas. A midiatização do turismo, nesse sentido, a passagem pelo tratamento das narrativas midiáticas, vai então 'cristalizando' imagens turísticas dos diversos destinos e também das práticas e vivências do turismo. Expressa-se, aqui, o que, no Jornalismo, tem sido chamado de Teoria do Agendamento ou Agenda Setting.

Trata-se da teoria segundo a qual os meios de Comunicação agendam o que pensar, o que fazer. Pode-se dizer, nesse sentido, que os meios de comunicação agendam as significações e interpretações da realidade, por parte da sociedade. Essa teoria tem origem remota na década de 1970, no pensamento da dupla de pesquisadores Maxwell McCombs e Donald Shaw, a quem é atribuída. Há, no entanto, outros estudos que sustentam, na origem das pesquisas sobre o assunto, a ideia de que a veiculação na mídia gera determinadas e específicas interpretações. É o caso, por exemplo, do trabalho de Walter Lippmann, que, já em 1922, propôs a tese de que as pessoas não respondiam diretamente aos fatos do mundo real, mas que viviam em um pseudo-ambiente composto pelas "imagens em nossas cabeças". Em todo caso, a temática é recorrente nos estudos em Comunicação. Em coerência com as perspectivas contemporâneas desses estudos, entende-se que agendamento é inflexão, direcionamento narrativo, não uma imposição totalitária e unidirecional. Isso significa que a veiculação pela

\footnotetext{
5 As referências às transformações dos dispositivos tecnológicos em Comunicação são muitas. Destacam-se, aqui, algumas: Burke e Briggs (2004); Castells (1999); Giovannini (1987); Kerckhove (1997); Levy (1993); Marcondes Filho (1994; 1996); Postman (1994); Santaella (1992).
} 
mídia não define por si só, nem é segurança de construção da imagem do destino turístico. 0 que ocorre é processual e faz parte de uma complexa trama de fluxos significacionais, em que a mídia é um dos dispositivos recorrentes e intervenientes.

Outro aspecto é que a própria mídia vem se transformando, de tal forma que é preciso desbastar um imaginário coletivo de sua significação. Às vezes, a palavra 'a mídia' é repetida e lida como se fosse uma 'entidade abstrata', uma espécie de totem ${ }^{6}$ contemporâneo, capaz de concentrar e determinar todas as significações. Na prática, cada dia mais, ela vem se mostrando como uma trama midiática. A palavra mídia deriva de médium, em inglês, literalmente meios, ou seja, na sua matriz significacional, ela já é plural, múltipla. No cenário contemporâneo, fica muito claro que essa pluralidade e multiplicidade é quase infinita, quando se pensa em uma sociedade de redes midiáticas e na combinação de dispositivos comunicacionais, em cada meio, em cada dispositivo. São interconexões e interligações, que vão se ampliando e complexificando, de tal modo a se compreender que as narrativas, também as narrativas do turismo, são produzidas em meio a um emaranhado de dispositivos, que engendram vínculos complexos com os sujeitos envolvidos no turismo. Verifica-se, desse modo, que o agendamento, ainda que ocorra, não é algo 'dado', como óbvio, resultante de um processo mecânico, mas como resultado de um aprimoramento de trabalho com os fluxos informacionais e na apropriação de técnicas de narrativas que vão, essas sim, contribuindo para cristalizar significações.

Importante destacar aqui a relevância da narrativa, na constituição de uma existência em si - no caso, a constituição dos destinos e dos atrativos dos destinos turísticos. Desse modo, narrar uma experiência turística ou as narrativas midiatizadas do turismo são processos que criam significações em relação aos destinos. É o que fica claro, com a explicação de Sodré (2009: 26-27), sobre a narrativa, citando Blanchot (1959): “[...] não é o relato do acontecimento, mas o próprio acontecimento, a aproximação deste acontecimento, o lugar onde este é chamado a se produzir, acontecimento ainda por vir e por cujo poder de atração a narrativa pode esperar, também ela, realizar-se". Sodré (2009: 27) complementa: "Nesse caso, a narrativa é uma função, que cria aquilo mesmo que se narra, assim como quando se escreve uma obra de ficção ou se faz um filme".

O estudo das narrativas, inclusive, vem ganhando espaços em áreas de estratégia militar e econômica, no cenário mundial, como é o caso da agência Darpa (Defense Advanced Research Projects Agency), de tecnologia militar dos Estados Unidos, co-responsável pela invenção da internet. Esse direcionamento para o estudo das narrativas é apresentado em texto de Alexandro Martinez Gallardo, de 22 de outubro de 2011, intitulado "La neurobiología de las narrativas (o cómo contar historias es crear realidades)", em que são abordados aspectos da neurobiologia das narrativas e dos múltiplos interesses que a área de estudos vem despertando, seja por setores de estratégia de marketing ou de estratégias militares.

O texto menciona inclusive o fato de que a Darpa tem investido fortemente nos estudos da área, como ficou claro na conferência, intitulada Narrativa Networks (N2): The Neurobiology of Narratives. O presidente desta conferência, Coronel William Casebeer, chega a comparar o efeito das narrativas à adição de drogas. Ele expressa a posição da Darpa sobre a temática, lembrando que os fluxos narrativos internacionais podem ser importantes para definir posicionamentos dos sujeitos, em relação aos conflitos bélicos:

\footnotetext{
${ }^{6}$ O termo está sendo utilizado, aqui, no sentido atribuído por Freud (1913), no texto clássico Totem e Tabu, como a força que une o grupo e que concentra, em si, por isso mesmo, poderes especiais e na maioria das vezes não bem compreendidos, a não ser pelos líderes da tribo.
} 


\begin{abstract}
O impacto das narrativas na psicologia humana envolve desde eventos que lembramos com maior facilidade até nossas decisões sobre importantes condutas fundantes que definem nosso grau de confiança nos demais. Já que o cérebro humano é a causa próxima de nossas ações, as narrativas têm um impacto direto nos processos neurobiológicos dos receptores e emissores. Entender como as narrativas informam os processos neurobiológicos dos receptores e dos emissores. Entender como as narrativas informam os processos neurobiológicos é crítico se queremos determinar que efeito têm sobre a psicologia e a neurobiologia das decisões humanas e seus comportamentos, e podem ajudar em tudo o que vai desde explorar como o transtorno de estresse pós-traumático está influenciado pela repetição do evento, até entender os pensamentos e sentimentos de outras pessoas. (Casebeer, 2011: 1)
\end{abstract}

Considera-se essa abordagem, mas na perspectiva dos ecossistemas comunicacionais e turísticos, o que implica a não totalização ou mecanização dos efeitos. Isso significa a compreensão da lógica processual dos processos e da incerteza inerente aos fenômenos. Assim, a narrativa não é uma imposição totalitária, mas é preciso compreender que ela propõe e, às vezes, provoca inflexões de leituras, tendências de direcionamentos. Isso tem implicações em todas as áreas da vida, inclusive, claro, no turismo, em que os direcionamentos, mobilizações e desterritorializações implicam o tempo todo em leituras e releituras do mundo, especialmente as produzidas coletivamente.

Um dos teóricos expoentes da Esquizoanálise, Guattari (1992: 102), afirma: "O mundo só se constitui com a condição de ser habitado por um ponto umbilical de desconstrução, de destotalização e de desterritorialização, a partir do qual se encarna uma posicionalidade subjetiva". A fala remete a diferentes processos, desde as explosões geradoras de universos, com a desconstrução das estrelas, até os processos autopoiéticos e desterritorializantes, vivenciados pelos sujeitos em movimento, portanto, no turismo e na comunicação. A reflexão possibilita pensar os processos vivenciados por sujeitos, grupos, movimentos sociais, o que envolve a eclosão de processos subjetivos, de sujeitos singulares e também coletivos.

\title{
4. Rumo à amorosidade no turismo
}

A noção de amorosidade está no centro da discussão empreendida pelo Amorcomtur!. Ela constitui e direciona o grupo. Amorosidade na Comunicação e no Turismo e suas transversalidades. Por vezes, para algumas pessoas ainda não familiarizadas com a abordagem, o termo pode soar estranho, pela histórica carga significacional. Mesmo considerando esses aspectos, o Amorcomtur! vem se questionando e construindo o questionamento enunciador: “E por que não falar de amor?", enfrentando algumas resistências. No que se refere à associação da temática do amor com a Ciência e a Educação, como grandes campos em que se produz conhecimento, há referenciais importantes que contribuem para fundamentar as discussões: Paulo Freire (1987; 1996), Morin (2003), Prigogine (2009), Maturana (1998), Bauman (2004), Restrepo (1998), Barthes (1986), para citar apenas alguns.

A associação Ciência-Amor-Turismo-Comunicação só pode ser lida como ingênua, pelo desgaste da palavra amor, pela sua histórica desvalorização nos centros de produção, na lógica produtiva do Capitalismo Mundial Integrado, na suposta 'evolução' de um modelo de trocas e relações produtivas, denominado de 'capitalismo por espoliação' (Harvey, 2005). São vários os pensadores que sinalizam, no entanto, em diversas áreas, a crise, a falência, do modelo produtivista a qualquer custo, que espolia e destrói e desconsidera a nossa humana condição 
e a ecologia em sentido amplo.7 Há poucas chances de sobrevivência para a humanidade, para o planeta, considerando a lógica evolucionista, racional e objetivista da Ciência Clássica e dos modelos produtivos implantados desde o fordismo, passando pelo toyotismo, até uma 'onda' mundial de busca de qualidade total em que se enuncia que 'errar não é humano’. Em várias áreas do conhecimento, vai surgindo a consciência de necessidade de outras práticas relacionais, dos sujeitos entre si, dos sujeitos com o trabalho, com o consumo, com o lixo, com o ambiente em sentido amplo. Maturana (1998:23-24) afirma que o "amor é o reconhecimento do outro como legítimo outro na convivência" e que não há separação entre emoção e razão. A emoção é o que aciona a ação, o que põe o sujeito em ação, até mesmo nas situações aparentemente mais racionais. Ora, se o outro é legítimo outro, o princípio ético, de respeito às condições de cada sujeito envolvido, tem que ser o platô referencial das relações, na vida, e, claro, também dos processos comunicacionais. Segue a fala de Maturana (ibid.): "O amor é a emoção que constitui o domínio de condutas em que se dá a operacionalidade da aceitação do outro como legítimo outro na convivência, e é esse modo de convivência que conotamos quando falamos do social. [...] Sem a aceitação do outro, não há fenômeno social”.

Assim, Turismo e Comunicação, portanto, a midiatização do turismo precisa partir desse pressuposto, já que as relações se produzem em função de 'coordenações de relações', que se estabelecem no entrelaçamento de sujeitos. Os processos turísticos e comunicacionais se fazem com o agenciamento de redes de afetos e movimentações de sujeitos que, ao se desterritorializarem, vibram, estremecem, movimentando campos de forças, a partir de múltiplos e muitos investimentos, em conexão com ecossistemas complexos e amplos. Esses campos se compõem, em delineamento e inflexão, em planos de significação emergente e com potência de devir. Então, misturam-se, mesclando-se, produzindo, aí sim, sentidos partilhados, renovados, reinventados, a partir da mistura de 'corpos vibráteis' que são espécies de intensidades físicas, materiais e abstratas, energias-potência, vamos chamar assim. Depois que os sujeitos se desterritorializam e se encontram, se reterritorializam, na Comunicação ou no Turismo, 'nada será como antes', as transformações, por mais ínfimas que pareçam, alteram universos existenciais e reverberam para múltiplos outros universos. Isso também é o que mantém potente o desejo de que novos processos sejam agenciados.

Desse modo, os grandes sinalizadores para a mutação das narrativas turísticas, que valorizam os territórios turísticos, também não são específicos do campo da narrativa, mas estão em consonância às mutação cósmica planetária, ${ }^{8}$ de busca de transmutação da lógica da competição para a da cooperação, de respeito ao 'mundo do Outro', já que este é legítimo e outro, portanto, diferente, diverso. Isso, por si só, tem a potência de reinvenção mútua, de acionamento de potências, com resultados que podem vir a beneficiar grandemente todos os sujeitos e territórios envolvidos nos processos de turismo. Trocar a espoliação exacerbada pela mídia, ${ }^{9}$ pela ética do culto ao encontro, ao conhecimento e respeito às diferenças, à compreensão de que somos 'um', somos sujeitos imersos na teia da vida, nômades por

\footnotetext{
7 Interessante, nesse sentido, a perspectiva de Martínez-Alier (2007), com os ciclos do movimento ambientalista e a noção de Justiça Ambiental, que representa um avanço em relação ao chamado desenvolvimento sustentável, que prevê o estabelecimento da correlação de valor, para o ambiente, visando a sua preservação para as gerações futuras.

${ }^{8}$ A expressão 'mutação cósmica planetária' pode ser compreendida, claramente, no documentário intitulado Crossroads: Dores de Parto de Uma Nova Visão Mundial (Crossroads, 2016).

9 Neste caso, a expressão 'espoliação exacerbada pela mídia' corresponde aos fluxos narrativos expressos pela trama de mídias, em nível mundial, que sugere e enaltece a naturalização do modelo capitalístico, da lógica do consumo desenfreado, da valorização do indivíduo e do capital.
} 
excelência e que temos na amorosidade nosso trampolim para o futuro e, ao mesmo tempo, nosso porto existencial. As narrativas devem se pautar pela disposição do encontro, pela não competição, pela subjetivação dos discursos, pelo mergulho na captação sensível das condições, caraterísticas, dos atributos naturais, históricos e culturais. Precisam ser pautadas pelo encantamento pelo outro, o olhar de 'ad-miração', e o relato cuidadoso, feito com esmero de quem conta a viagem, considerando a intensidade anímica que a moveu, que a produziu.

\section{Considerações finais}

Refletiu-se, neste artigo, os processos de midiatização e sua vinculação com a trama comunicacional contemporânea, como conjunto de produções comunicacionais complexas, entrelaçadas em rede planetária. Buscou-se considerar o fato de que a midiatização do turismo ocorre em ecossistemas comunicacionais também complexos, em conexão com os processos produtivos capitalísticos, portanto, que estão à mercê das condições do que Harvey (2005) chama de capitalismo por espoliação. Assim, entende-se uma trajetória turística que, ao mesmo tempo, significa aprimoramento de processos inerentes ao turismo, sofisticação tecnológica, mas que 'inspira cuidados', do ponto de vista da ética da relação e do cuidado com o Outro (sendo esse outro as outras pessoas, os outros territórios, enfim, os outros ecossistemas com os quais se interage, quando em processo de turismo).

A engrenagem maquínica midiática produz midiatizações turísticas em conexão com as grandes máquinas capitalísticas, que movimentam capitais diversos, desde financeiros até os valores imateriais, relacionados à cultura ou às emoções. São engrenagens de diversas 'naturezas, substâncias e matérias'. Todas potentes em princípio e que tem sua potência direcionada para os interesses do grande capital e dos focos de poder político. Assim, do mesmo modo que se definem os fluxos informacionais em geral, definem-se os focos de midiatização turística. Os grandes conglomerados definem o que enfatizar, destacar, sugerir dos destinos turísticos, em consonância com a grande engrenagem publicitária, os grandes investimentos do turismo na própria mídia. Desse modo, ecossistema midiáticocomunicacional e turístico reiteram-se mutuamente, formando entrelaçamentos, cuja orientação é a da espoliação e de priorização da acumulação de capital, pelos grandes conglomerados ou por territórios historicamente delimitados pela geopolítica internacional, nacional, regional e local. Enfim, se não houver avanços nas reflexões... segue-se uma espécie de círculo vicioso e de conveniências recorrentes.

Nessa lógica, a midiatização atribui valor aos destinos, destacando determinados atrativos. Isso nem sempre significa a valorização da cultura local, o respeito, a ética, com relação aos sujeitos e ao patrimônio envolvido. Muitas vezes, ocorre um processo de mercantilização cultural, que coloca em jogo a valorização da cultura, da natureza, das tradições históricas. Corre-se o risco, neste caso, de profundas alterações nos ecossistemas turísticos, com produções de 'destinos fachada', para 'turistas-relâmpago', no acionamento e confluência de ações mercadológicas que transformam os lugares e suas singularidades em 'mercadoria-objeto', que continua considerando o turista como 'público-alvo'.

O contraponto a essa perspectiva é a emergência de uma visão pautada pela ética da relação, pela responsabilidade social, com vistas à sustentabilidade, com orientação de outra consciência planetária. É o que, no Amorcomtur!, se denomina como perspectiva de amorosidade e autopoiese. Assim, a proposta de desenvolvimento e orientação para um 
'turismo amoroso-autopoiético' surge comprometida com a nova consciência planetária, ${ }^{10}$ que está em consonância ao que venho chamando de cenário da mutação da Ciência, bem como à mutação de atitude (no sentido de ato no todo), em termos globais, envolvendo desde as nossas ações cotidianas, nossos planejamentos existenciais, nossos relacionamentos, pessoais e profissionais, nossos vínculos e, claro, nossos deslocamentos, nossa tendência à desterritorização, nossa condição nômade, nosso ‘tour-ismo'.

\section{Referências bibliográficas}

Akerlof, G. \& Shiller, R. (2009). O espírito animal: Como a psicologia humana impulsiona a economia e sua importância para o capitalismo global. São Paulo: Elsevier.

Baptista, M. L. C. (2000). O sujeito da escrita e a trama comunicacional. Um estudo sobre os processos de escrita do jovem adulto como expressão da trama comunicacional e da subjetividade contemporânea (Tese de dotouramento não publicada). Universidade de São Paulo, Brasil.

Barthes, R. (1986). Fragmentos de um discurso amoroso. Rio de Janeiro: F. Alves.

Bauman, Z. (2004). Amor líquido: sobre a fragilidade dos laços humanos. Rio de Janeiro: Jorge Zahar.

Burke, P. \& Briggs, A. (2004). Uma história social da mídia: De Gutenberg à Internet. (Trad. M. C. P. Dias) Rio de Janeiro: Jorge Zahar.

Capra, F. (1991). O Ponto de mutação. A ciência, a sociedade e a cultura emergente. São Paulo: Cultrix.

Capra, F. (1997). A Teia da vida. Uma nova compreensão dos sistemas vivos. São Paulo: Cultrix.

Casebeer, W. (2011) Special Notice DARPA-SN-11-25 Narrative Networks (N2): The Neurobiology of Narratives.

Castells, M. (1999). A sociedade em rede. A era da informação: Economia, sociedade e cultura. (Trad. R. V. Majer). São Paulo: Paz e Terra.

Colferai, S. A. (2014). Um jeito amazônida de ser mundo - A Amazônia como metáfora do ecossistema comunicacional: Uma leitura do conceito a partir da região. (Tese de doutoramento não publicada). Universidade Federal do Amazonas, Brasil.

Crossroads (2016). Dores de parto de uma nova visão mundial. [video].

Freire, P. (1987). Pedagogia do oprimido (17 $7^{\mathrm{a}}$ ed.). Rio de Janeiro: Paz e Terra.

Freire, P. (1996). Pedagogia da autonomia: Saberes necessários à prática educativa. São Paulo: Paz e Terra.

Freud, S. (1996). Totem e Tabu. (Trad. Ó. C. Muniz). [Original publicado em 1913]. In J. Salomão (Ed.) Edição standard brasileira das obras psicológicas completas de Sigmund Freud. (Vol. XIII, pp. 13-168). Rio de Janeiro: Imago.

Gallardo, A. M. (2011). La neurobiología de las narrativas (o cómo contar historias es crear realidades).

Giovannini, G. (1987). Evolução na comunicação: Do sílex ao silício. Rio de Janeiro: Nova Fronteira.

Goldim, J. R. (1999). Ecologia profunda. Disponível em http://www.bioetica.ufrgs.br/ecoprof.htm

Guattari, F. (1992). Caosmose: Um novo paradigma estético. Rio de Janeiro: Editora 34.

Harvey, D. (2005). A produção capitalista do espaço. (Trad. C. Szlak). São Paulo: Annablume.

Kerckhove, D. (1997). A pele da cultura. Uma investigação sobre a nova realidade electrónica. Lisboa: Relógio D'água.

Levy, P. (1993). As tecnologias da inteligência. O futuro do pensamento na era da informática. São Paulo: Editora 34.

Magalhães, L. H. (2016). Panorama histórico do turismo: Do mundo moderno a contemporaneidade. Disponível em http://www.obsturpr.ufpr.br/EPTUR/PANORAMA\%20HISTRICO\%20DO\%20 TURISMO.pdf

Marcondes Filho, C. (1994). A sociedade tecnológica. São Paulo: Scipione.

Marcondes Filho, C. (1996). Pensar-pulsar. Cultura comunicacional, tecnologias, velocidade. Coletivo NTC. São Paulo: Edições NTC.

Martínez-Alier, J. (2007). O Ecologismo dos pobres: Conflitos ambientais e linguagens de valoração. São Paulo: Contexto.

Maturana, H. (1998). Emoções e linguagem na educação e na política. (Trad. J. F. C. Fortes). Belo Horizonte: UFMG.

\footnotetext{
${ }^{10}$ Refiro-me, aqui, à emergência de uma nova consciência, em sentido global. A mutação sinalizada está expressa, por exemplo, no documentário Crossroads: Dores de Parto de Uma Nova Visão, já mencionado, anteriormente.
} 
Monteiro, G. V. \& Colferai, S. A. (2011). Por uma pesquisa amazônida em Comunicação: provocações para novos olhares. In Malcher, M., Seixas, N., Lima, R. \& Amaral Filho, O. (Eds.). Comunicação midiatizada na e da Amazônia. Belém: FADESP.

Morin, E. (2003). Amor, poesia e sabedoria. Rio de Janeiro: Bertrand Brasil.

Postman, N. (1994). Tecnopólio: A rendição da cultura à tecnologia. São Paulo: Nobel.

Prigogine, I. (2009). Ciência, razão e paixão. São Paulo: Livraria da Física.

Restrepo, L. C. (1998). O Direito à ternura. Petrópolis: Vozes.

Santaella, L. (1992). Cultura das mídias. São Paulo: Razão Social.

Sodré, M. (1987). Televisão e psicanálise. São Paulo: Ática.

Sodré, M. (2009). A narração do fato: Notas para uma teoria do acontecimento. Petrópolis: Vozes.

Stropper, M. T. D. (2012). O capitalismo pós-199o e a emergência de novos pólos de poder. Disponível em http://seer.ufrgs.br/paraonde/article/viewFile/2

Stropper, M. T. D. (2014). Inflexão das ONGs ambientalistas após 1990: Um estudo sobre a atuação das ONGs no caso da Usina Hidrelétrica Belo Monte (Tese de doutoramento não publicada), Universidade Federal do Rio Grande do Sul, Brasil.

MARIA LUIZA CARDINALE BAPTISTA é doutora em Ciências da Comunicação, pela ECA/USP. Professora e pesquisadora do Programa de Pós-Graduação em Turismo e Hospitalidade da Universidade de Caxias do Sul (BRASIL). Pesquisadora com apoio CNPq. Coordenadora do Amorcomtur! Grupo de Estudos em Comunicação, Turismo, Amorosidade e Autopoiese (CNPq-UCS) e integrante do Filocom (ECA/USP). Pósdoutoranda, Professora Colaboradora e Pesquisadora visitante sênior da Universidade Federal do Amazonas (UFAM), com apoio FAPEAM. Pesquisadora Iberoamericana (edital UCS/SANTANDER). Endereço: Rua Santos Dumont, 51 - Apto 203, Nossa Senhora de Lourdes, Caxias do Sul/RS - Brasil. CEP: 95084-390.

Submetido em 15 setembro 2016

Aceite em 18 abril 2017 